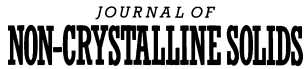

\section{Surface nucleation and growth in Anorthite glass}

\author{
Elmar Wittman ${ }^{1}$, Edgar Dutra Zanotto * \\ Vitreous Materials Laboratory - LaMaV, Department of Materials Engineering - DEMa, Federal University of São Carlos-Ufscar, \\ 13.565-905, São Carlos-SP, Brazil
}

Received 7 September 1999; received in revised form 8 November 1999

\begin{abstract}
Qualitative and quantitative studies of surface nucleation and growth were carried out with a glass having a composition close to Anorthite $\left(\mathrm{CaO} \cdot \mathrm{Al}_{2} \mathrm{O}_{3} \cdot 2 \mathrm{SiO}_{2}\right)$. Quasi-isometric hexagonal and elongated hexagonal crystals assumed to belong to the same phase, and a few rectangular crystals were observed after continuous or cumulative (intermittent) thermal treatments. The EDS analysis revealed that the chemical compositions of the hexagonal morphologies were similar to the mother glass composition. The number density on the surface, $N_{\mathrm{s}}$ (crystals $/ \mathrm{m}^{2}$ ), and the relative concentration of the different morphologies depended on the type of polishing powder used to prepare the glass surfaces. Low magnification optical micrographs showed preferential nucleation of crystals along surface scratches. These qualitative experiments indicate that heterogeneous nucleation predominates. Some quantitative analyses were carried out for specimens polished with cerium oxide before heat treatment. The crystal nucleation curves at $960^{\circ} \mathrm{C}$ $\left(T_{\mathrm{g}} \sim 850^{\circ} \mathrm{C}\right)$ revealed an apparent transient period, $\tau_{\mathrm{A}}$, of a few hours. That period was mainly due to the time needed for growth of nuclei from the critical size $\left(d^{*} \sim 1-2 \mathrm{~nm}\right)$ to detectable dimensions $(\varepsilon \sim 1-2 \mu \mathrm{m})$. For continuous treatments, there was a tendency to saturate $N_{\mathrm{s}}$. Growth kinetics were determined for isolated crystals growing on the external surfaces and for the crystalline layer growing towards the specimen center. These growth velocities were equal, within the error limits. This behavior indicates that the mechanisms of interfacial rearrangements controlling crystal growth on the surface and inside the glass are the same and corroborates previous studies for Cordierite glasses. () 2000 Elsevier Science B.V. All rights reserved.
\end{abstract}

\section{Introduction}

Despite its common occurrence and predominance over bulk crystallization, surface crystallization of glass has not received the attention it deserves [1,2]. Recently, however, much has been learned about surface crystallization thanks to an international collaborative effort organized by the

\footnotetext{
${ }^{*}$ Corresponding author. Tel.: +55-162 608 250; fax: +55-162 615 404; www.nit.ufscar.br/lamav.

E-mail address: dedz@power.ufscar.br (E.D. Zanotto).

${ }^{1}$ Present address: Vitrofarma (Schott Glaswerk), Rio de Janeiro, Brazil.
}

Nucleation, Crystallization \& Glass-Ceramics Committee (TC-7) of the ICG. However, there are still several open issues [3-5], such as: Is heterogeneous nucleation the sole mechanism of surface crystallization for all glasses? What is the nature of the active nucleation sites? How do surface crystallization kinetics compare with volume crystallization kinetics in a given glass?

Most of the results the TC-7 Committee has achieved refer to Cordierite glasses. Hence, by studying a different system that, nonetheless, has crystals with morphologies similar to those existing in heat-treated Cordierite glasses, one may be able to consolidate the findings of the TC-7. This 
communication describes a systematic study of surface nucleation and growth kinetics in an almost stoichiometric glass, close to Anorthite $\left(\mathrm{CaO} . \mathrm{Al}_{2} \mathrm{O}_{3} \cdot 2 \mathrm{SiO}_{2}\right)$. This composition was chosen due to its high chemical durability, which would minimize any alteration of the glass surface during the period of study. Additionally, the study of Anorthite glass could allow us to examine crystal growth behavior similar to that found in Cordierite glasses where, analogously, hexagonal crystals first grew in isolated form on the surface and, after impingement, the compact surface layer grew towards the interior of the glass with a well-defined crystallographic texture.

The specific objectives of this paper were: (i) to test the surface crystallization mechanism (homogeneous vs. heterogeneous nucleation) and (ii) to examine the crystal growth behavior of different fronts, similar to those found in Cordierite glasses - isometric hexagons, elongated hexagons and rectangular crystals, growing isolatedly on the surface, and the surface layer growing towards the interior of the glass. The purpose of both these objectives is to either generalize or not, the findings of the TC-7 Committee for surface crystallization of Cordierite glass.

\section{Materials and methods}

Reagent grade $\mathrm{CaCO}_{3}, \mathrm{Al}_{2} \mathrm{O}_{3}$ and silica sand were mixed and melted in a platinum crucible, in a gas-fired furnace, at $1600^{\circ} \mathrm{C}$ for $5 \mathrm{~h}$. The viscous liquid was poured and pressed between two steel plates to obtain glass plates of about $2 \times 10 \times 20$ $\mathrm{mm}^{3}$. The glass composition, analyzed by EDS, was $24.1 \mathrm{CaO}, 26.1 \mathrm{Al}_{2} \mathrm{O}_{3}, 49.9 \mathrm{SiO}_{2} \mathrm{~mol}^{\%}$, which is close to stoichiometric Anorthite: $25 \mathrm{CaO}, 25$ $\mathrm{Al}_{2} \mathrm{O}_{3}, 50 \mathrm{SiO}_{2}$.

The specimens were broken into $2 \times 5 \times 5 \mathrm{~mm}^{3}$ pieces for further study. Mechanically polished (MP) specimens were obtained by grinding with $\mathrm{SiC}$ and polishing with $\mathrm{CeO}_{2}$ powder. The polished surfaces were cleaned with cotton wool soaked in acetone before heat treatment. 'Fire polished' (FP) specimens were obtained by heating glass pieces to $T=1560^{\circ} \mathrm{C}\left(T>T_{\text {liquidus }}\right)$ for $30 \mathrm{~min}$ and cleaning them with acetone-soaked cotton wool before treatment. Crystallization treatments were performed in air at $960 \pm 2{ }^{\circ} \mathrm{C}\left(T_{\mathrm{g}} \sim 850^{\circ} \mathrm{C}\right)$, in a fireclay tube furnace.

Two annealing strategies were employed, i.e., continuous and cumulative thermal treatments. In the continuous treatments, the same glass piece was continuously annealed for a defined time. In the cumulative treatments, the specimens were first annealed for $3 \mathrm{~h}$, quenched, analyzed under a microscope, heated for an additional hour, reanalyzed and so on. Three distinct regions, located around internal bubbles and used as references, were studied for each additional treatment, i.e., for $3+1+1+1+1+1 \mathrm{~h}$ at $960^{\circ} \mathrm{C}$, respectively. Both transmitted light and reflected light optical microscopy were used to characterize the resulting microstructures.

\section{Results}

\subsection{Qualitative studies}

Surface nucleation occurred preferentially on all specimens. Figs. 1(a) and (b) show a SEM and an optical micrograph, respectively, of a glass treated continuously for $7 \mathrm{~h}$ at $960^{\circ} \mathrm{C}$. Different crystal morphologies are clearly seen; elongated and almost regular hexagons and some small rectangular crystals. A semi-quantitative EDS analysis revealed that the chemical compositions of the hexagons were similar to the mother glass composition. It should be pointed out, however, that the estimated penetration depth of the electron beam was $\sim 2 \mu \mathrm{m}$ and the largest crystal sizes in the sample tested were about $5 \mu \mathrm{m}$ thick. Thus, the electrons were focused on and detected mainly the crystals, although some glass phase may also have been probed. Despite these restrictions, we assume here that the elongated and regular hexagons refer to different crystal orientations of the same phase (presumably Anorthite).

The number and shape of crystals varied significantly with the polishing powder used to prepare the sample surfaces. For instance, with the usual cerium oxide powder (actually a mixture of rare earth oxides), the most frequent morphology was elongated hexagons while, if a cerium oxide 

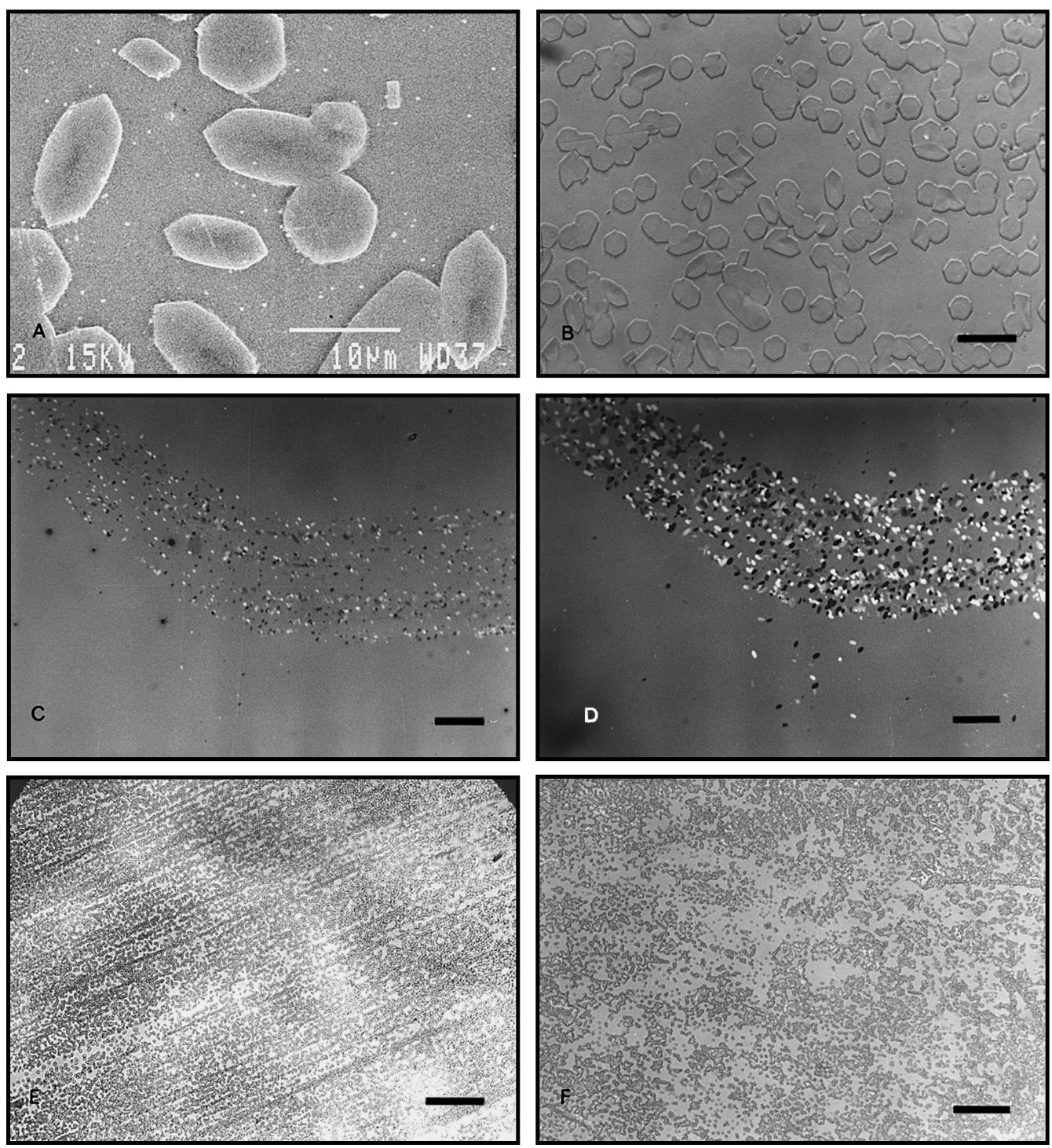

Fig. 1. (a) SEM micrograph of a glass treated continuously for $7 \mathrm{~h}$ at $960^{\circ} \mathrm{C}(\mathrm{SE}-15 \mathrm{kV})$. (b) Optical micrograph of a glass treated continuously for $7 \mathrm{~h}$ at $960^{\circ} \mathrm{C}$. (c) Scratched glass piece treated for $1 \mathrm{~h}$ at $960^{\circ} \mathrm{C}$. (d) Scratched glass piece treated for $(1+1) \mathrm{h}$ at $960^{\circ} \mathrm{C}$. (e) MP glass treated for $3.5 \mathrm{~h}$ at $960^{\circ} \mathrm{C}$. (f) $\mathrm{FP}$ glass treated for $3.5 \mathrm{~h}$ at $960^{\circ} \mathrm{C}(\mathrm{Bar}=20 \mu \mathrm{m}$ for figures (b)-(f)). The samples were etched with diluted HF before photographing.

powder from a different source was used, an approximately equal number of elongated hexagons and rectangular crystals occurred. A much larger number of crystals appeared in the case of alumina-polished glass. These findings are qualitatively similar to those reported by Müller for a Cordierite glass [5].
Figs. 1(c) and (d) underscore the idea of heterogeneous nucleation on the glass surface. A firepolished sample was scratched in a circular motion using a hard metal instrument and wiped with cotton wool. After treating the scratched piece for only $1 \mathrm{~h}$ at $960^{\circ} \mathrm{C}$, most of the crystals were grouped around the scratch (Fig. 1(c)). After 
further treatment $\left(1+1 \mathrm{~h}\right.$ at $\left.960^{\circ} \mathrm{C}\right)$, the crystals grew in size but remained distributed around the same scratch, Fig. 1(d).

Figs. 1(e) and (f) show typical differences between MP and FP glass, wiped with acetonesoaked cotton wool and treated for $3.5 \mathrm{~h}$ at $960^{\circ} \mathrm{C}$. The crystals in MP specimens are clearly aligned in some preferential direction. The FP sample, on the other hand, presents a random distribution of crystals.

Few crystals were observed in the specimen volume with long treatment times $(t>70 \mathrm{~h})$. Hishinuma [6] also observed internal nucleation in Anorthite glass after relatively high induction times (the author did not mention if a gas or an electric furnace, which significantly affects the $\mathrm{OH}$ content, was used to melt his glass [6]). Crystallization was found on the inner surfaces of some internal bubbles; however, most of them were totally free of crystals. Similar behavior was observed in a study of $\mathrm{BaO}-\mathrm{SiO}_{2}$ glasses [7] and by Völksch [8] for a Cordierite glass.

\subsection{Quantitative studies}

Fig. 2 shows the number density of crystals $\left(N_{\mathrm{s}}\right.$ (crystals $/ \mathrm{m}^{2}$ ), sum of all morphologies, dominated by the hexagons) for MP surfaces as a function of treatment time at $960^{\circ} \mathrm{C}\left(T_{\mathrm{g}} \sim 850^{\circ} \mathrm{C}\right)$ for both continuous and cumulative treatments. The curve for continuous treatments $(\boldsymbol{\Delta})$ increases with time but deviates from a straight line and tends to saturate. The curve for cumulative treatments

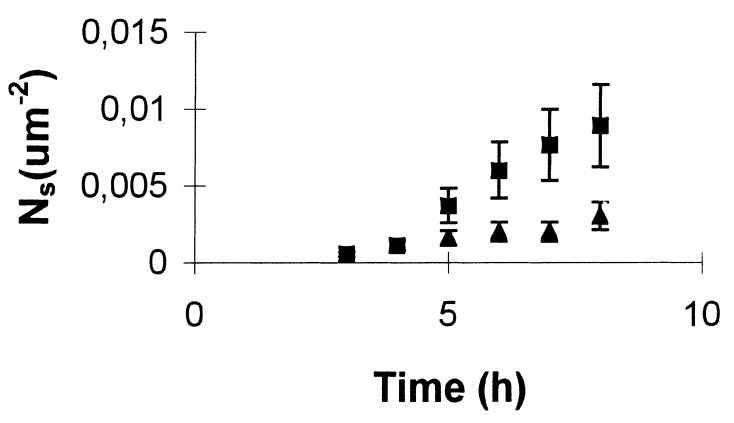

Fig. 2. $N_{\mathrm{s}}$ (all morphologies) for MP surfaces for continuous $(\boldsymbol{\Delta})$ and cumulative ( $\boldsymbol{\square})$ treatment. The first data point belongs to both series.

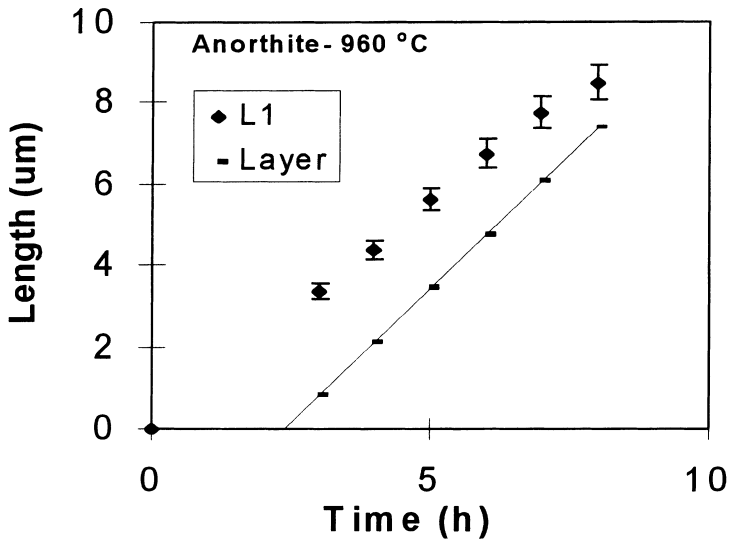

Fig. 3. Maximum crystal size as a function of treatment time. $(\checkmark)$ : Half-length of the major axis (L1) of the largest elongated hexagons (cumulative treatments); (_ $)$ : crystallized surface layer, layer (continuous treatments).

rises to higher values of $N_{\mathrm{s}}$. No crystals could be detected below $3 \mathrm{~h}$.

Fig. 3 shows the crystal growth plots for the elongated hexagons on the surface and the extrapolated plot (from data points taken after long treatments, 22-99 h) for the thickness of the crystallized layer obtained with cumulative treatments at $960^{\circ} \mathrm{C}$. The crystal growth velocities estimated from the curve slopes are equal, within the error limits; $1.1 \pm 0.2 \mu \mathrm{m} / \mathrm{h}$ for the (half-length) of the major axis of the largest elongated hexagons growing freely on the glass surface; and $1.3 \pm 0.2$ $\mu \mathrm{m} / \mathrm{h}$ for the crystallized layer, respectively. An apparent induction time of about $(2.5 \pm 2.0) \mathrm{h}$ is seen in the plot for the crystal layer, however, it is subjected to significant uncertainty because the line was extrapolated. Hence, one cannot rule out the hypotheses that the induction time is close to zero, as found for the isolated crystals.

\section{Discussion}

Crystallization was found on the inner surfaces of some internal bubbles; however, most of them were free of crystals. It is possible that solid contaminants survived the melting process inside some bubbles or that some chemical compounds (e.g., carbonates or sulfates) form during cooling of the 
bubble gas, which could then act as substrates for heterogeneous nucleation of the main crystal phase.

On MP specimens, the surface crystals are clearly aligned in a preferential direction. This is probably a consequence of remnants left in aligned scratches resulting from the grinding and polishing operations and indicates the heterogeneous nature of surface crystallization in Anorthite glass. It is also possible that the elastic strain energy $\left(W^{\varepsilon}\right)$ arising on nucleation due to the density difference between crystal and mother glass (which decreases the work of nucleation) does not relax completely before nucleation. In this case, Schmeltzer and Gutzow recently demonstrated that $W^{\varepsilon}$ is minimized at the scratch edges, thus favoring nucleation along scratches (over volume nucleation or nucleation on perfectly flat surfaces) [9].

The micrographs in Figs. 1(c-e) clearly show preferential nucleation at special sites. This indicates that crystallization is governed by heterogeneous nucleation. As shown in Fig. 2, $N_{\mathrm{s}}$ shows a tendency to saturate for prolonged continuous annealing, demonstrating that nucleation is probably restricted to a limited number of active nucleation sites. The same saturation phenomenon was observed in other glasses (e.g., Cordierite [5] and Diopside [10]), where a constancy of $N_{\mathrm{s}}$ with respect to the annealing condition was shown $[1,2,5,10]$.

The fact that $N_{\mathrm{s}}$ increases more significantly with time for cumulative treatments than for continuous treatments indicates that there is additional nucleation at each step of cumulative treatments. At least two possibilities may be addressed:

(i) Supplementary nucleation can occur in the heating path of each step of intermittent treatment if the maximum temperature of nucleation, $T_{\mathrm{N}}$, is lower than the final annealing temperature $\left(T_{\mathrm{A}}=960^{\circ} \mathrm{C}\right)$. As $T_{\mathrm{A}} / T_{\mathrm{M}}<0.65$ in the present case (where $T_{\mathrm{M}}$ is the equilibrium melting point and $T_{\mathrm{N}}$ is the maximum nucleation temperature, both in $\mathrm{K}$ ), this ratio is significantly lower than $T_{\mathrm{N}} / T_{\mathrm{M}}$ reported for surface-induced nucleation in other glasses. For instance, $T_{\mathrm{N}} / T_{\mathrm{M}} \sim 0.85$ for both $x$ phase and $\mu$-Cordierite crystals in a Cordierite glass. The high $T_{\mathrm{N}} / T_{\mathrm{M}}$ for surface nucleation compared to the ratio for homogeneous nucleation $\left(T_{\mathrm{N}} / T_{\mathrm{M}} \sim 0.55\right)$ is due to the low interfacial energy for surface nucleation [2,5]. Thus, it is unlikely that enhanced nucleation developed in intermittent treatments is due to a passage through a nucleation maximum in the heating path.

(ii) Another cause, the most probable one for increased nucleation in intermittent treatments, is repeated cumulative contamination with solid particles during each cycle.

It is difficult to define the nucleation time lag $(\tau)$ from the present data. For continuous single-stage treatments, an apparent induction time for nucleation, $\tau_{\mathrm{A}}$, is observed (Fig. 2), which is actually the time needed to detect the first-born crystals by optical microscopy. $\tau_{\mathrm{A}}$ consists of the time lag of nucleation, $\tau_{\mathrm{N}}$, plus the time required for the nuclei to grow from the critical size $\left(d^{*} \sim 1-2 \mathrm{~nm}\right)$ to dimensions close to the detection limit of the microscope $(\varepsilon \sim 1-2 \mu \mathrm{m}), \tau_{\mathrm{g}}$. In this case $\left(960^{\circ} \mathrm{C}\right)$, the crystal growth rate, $U$, is $\approx 1 \mu \mathrm{m} / \mathrm{h}$. Thus, $\tau_{\mathrm{g}} \sim \boldsymbol{\varepsilon} / \mathbf{U}$ is $\approx 2 \mathrm{~h}$, covering most of the observed time lag in Fig. 2.

The crystal growth velocities of the elongated hexagons and crystallized layer are equal within the error limits, which shows that long-range diffusion is not dominant in the case presented here. Hence, the mechanisms of interfacial rearrangement controlling crystal growth of the isolated crystals on the surface and in the glass bulk are the same.

An estimate of the fractional surface area crystallized was performed using the JMAK theory. Fig. 4 shows the surface area crystallized calculated by expression (1), which is valid for continuous nucleation and growth of quasi-elliptical crystals (elongated hexagons):

$\alpha=1-\exp \left(-\pi U_{\mathrm{a}} U_{\mathrm{b}} I_{0} t^{3} / 12\right)$,

where $U_{\mathrm{a}}=2.165 \mu \mathrm{m} / \mathrm{h}$ and $U_{\mathrm{b}}=1.079 \mu \mathrm{m} / \mathrm{h}$ are the growth rates of the major and minor axes of the ellipsoidal crystal, respectively, and $I_{0}=$ $0.0018 / \mu^{2} \mathrm{~h}$ (the initial slope of the curves of Fig. 2).

Fig. 4 indicates that the fractional surface area transformed is negligible after the corresponding induction times of about $2-3 \mathrm{~h}$ (observed in the 


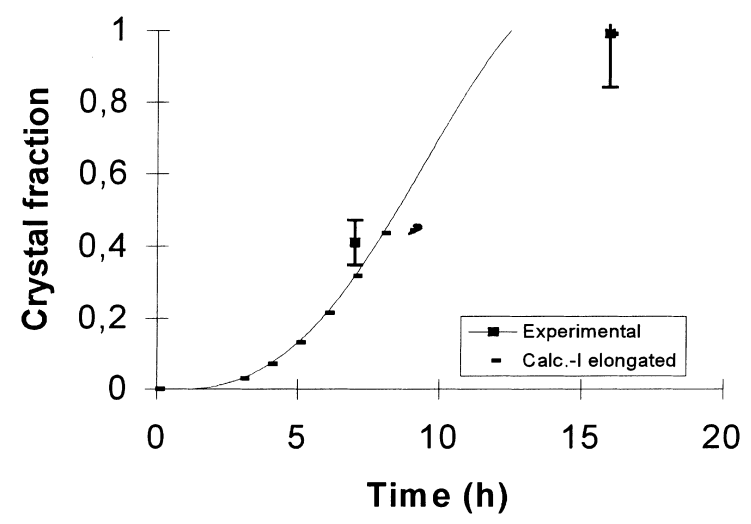

Fig. 4. Fractional surface area crystallized (continuous line $=$ calculated curve, square $=$ experimental point $)$.

nucleation curve, Fig. 2, and perhaps in the crystal growth curve, Fig. 3). Thus, the growth of the surface layer probably initiates in the very early stages of crystallization. A detailed study about this phenomenon will be discussed in [11].

\section{Conclusions}

Surface nucleation occurs heterogeneously at particular sites on the surface of Anorthite glass. The crystals are aligned in a preferential direction on MP specimens. Spurious crystallization was found on the inner surfaces of some internal bubbles; however, most of them were free of crystals, confirming that pristine surfaces are not preferred nucleation sites. The differences between nucleation behavior in cumulative and continuous treatments are the result of repeated, cumulative, contamination with solid particles at each additional heating of the cumulative treatments.

The crystal growth velocity of the isolated crystals on the surface is equal, within the error limits, to that of the crystallized surface layer growing towards the specimen center. This behavior indicates that long-range diffusion is not dominant in this case, and that the mechanisms of interfacial rearrangements controlling crystal growth of the isolated crystals on the surface and in the glass bulk are the same.

This study contributes toward the generalization of the findings of the TC-7 Committee for the surface crystallization behavior of Cordierite glasses.

\section{Acknowledgements}

The authors acknowledge Ralf Müller (BAM Berlin), G. Völksch (Friedrich Schiller University - Jena), Vladimir Fokin (Institute of Silicate Chemistry - St. Petersburg) and Paulo C. Soares Jr. (LaMaV - Ufscar) for their detailed analysis and critical remarks. The first three researchers mentioned above are members of the TC-7 Committee of the ICG. We are also indebted to CNPq, PRONEX and FAPESP (99/00871-2) for the financial support of this research.

\section{References}

[1] E.D. Zanotto, J. Non-Cryst. Solids 129 (1991) 183.

[2] E.D. Zanotto, in: Ceramic Transactions, vol. 30, USA, edited by Am. Ceram. Soc., 1993, pp. 65-74.

[3] G. Völksch, K. Heide, J. Non-Cryst. Solids 219 (1997) 119.

[4] V.M. Fokin, N.S. Yuritsin, V.N. Filipovich, A.M. Kalinina, J. Non-Cryst. Solids 219 (1997) 37.

[5] R. Müller, J. Non-Cryst. Solids 219 (1997) 110.

[6] A. Hishinuma, Crystal nucleation in glass-forming liquids, MSc thesis, MIT, USA, 1986.

[7] E.D. Zanotto, The effects of amorphous phase separation on crystal nucleation and growth in baria-silica and lithiasilica glasses, PhD thesis, Sheffield University, UK, 1982.

[8] G. Völksch, personal communication, São Carlos (1997).

[9] R. Müller, E.D. Zanotto, V.M. Fokin, presented at 9th Int. Conf. on the Physics of Non-Crystalline Solids, Tucson, AZ, USA, Oct. 1999, J. Non-Cryst. Solids (2000).

[10] E.D. Zanotto, J. Non-Cryst. Solids 130 (1991) 217.

[11] N. Diaz-Mora, E.D. Zanotto, R. Hergt, R. Müller, in: Proc. 4th Brazilian Symp. on Glasses and Related Material, Ouro Preto, MG, Brazil, Nov. 1999, J. Non-Cryst. Solids 273 (2000) in press. 